\title{
Enhance Light Oil Air Injection Recovery With High Efficiency Oxygen Consuming
}

\author{
Taichao Wang, Xin Li , XiaoyanLiu, DongWang \\ Institute of Petroleum Engineering, China University of Petroleum, \\ BeiJing, China \\ 22361450@qq.com
}

\begin{abstract}
Paper introduces the problems, challenges which light oil air injection faces, the meaning of high efficiency oxygen consuming and its key. From the result of indoor and outdoor experiments home and abroad, we analyse the mechanism of high efficiency oxygen consuming during air injection, how EOR effects and its affect factors. High efficiency oxygen consuming is significance to light oil air injection.
\end{abstract}

Keywords-air injection;EOR;high efficiency oxygen consuming;safety;well site

\section{I.INTRODUCTION}

Success of light oil reservoir air injection technology relies on two things: to improve oil recovery and consume the oxygen in air components, based on past experience, using air injection after water flooding development of flue gas such as $\mathrm{CO}_{2}$ and $\mathrm{N}_{2}$ displacement will increase by $6 \sim 10 \%$ of oil recovery. For air injection development process, the production of the light hydrocarbon components has not been completely consumed,which mixes of oxygen consumption, explosion danger will happen under certain conditions, put forward the efficient oxygen air injection development technology, designed to efficiently use oxygen and reduce the risk in the process of development.

\section{THE LIGHT OIL AIR INJECTION} DEVELOPMENT PRINCIPLE FEATURES

Until 1979, air injection development is mainly used in heavy oil development, without the artificial fracture of carbonate rocks in the process of the linear displacement [1-9]. Light oil air injection development is the use of high pressure oxidation flue gas produced by the light component of crude oil development, through the low temperature oxidation reaction to remove oxygen from the air, the temperature rise at the same time, reducing the viscosity of crude oil, with oil immiscible, under the condition of partially miscible or completely miscible to enhance oil flow ability, so as to improve recovery factor. Air injection development compared to other method to improve recovery efficiency in terms of operating costs, recovery efficiency and economic benefit has obvious advantages: [4, $10,11]$

(1)The air injection ability, forming effective stress more easily than water injection development system, gas inspiratory capacity is greater than the water absorbing capacity of low permeability reservoirs with low permeability and extremely low permeability reservoir has very good adaptability;

(2)After air injection, oxidizing reaction with crude oil, not only has the immiscible flooding effect also the heat generated by the flue gas can reduce oil viscosity, enhancing oil flow ability, with thermal expansion effect, so as to improve recovery factor;

(3)Air sources, the site operation-only a compressor can be carried out and its operation cost is far below the other gas $\left(\mathrm{N}_{2}, \mathrm{CO}_{2}\right.$, etc. development;

(4)The applicable reservoir type and geological conditions can use for the pattern area displacement and linear displacement, also can be used in vertical Wells, the secondary oil recovery and tertiary oil recovery process.

(5)For the development of offshore oil field, due to the limited space platform, steam injection supply ability is limited, wellbore loss is larger, development cost is high, so the air injection development is more feasible than steam injection development.

Fig .1 is a reaction light oil air injection reservoir characteristics in the development process diagram, as shown, in the reaction zone, oxygen and crude oil in this area is the main part of the oxygen consumption, the resulting flue gas $\left(\mathrm{N}_{2}, \mathrm{CO}_{2}\right.$, etc. $)$ as the main force of oil displacement. 


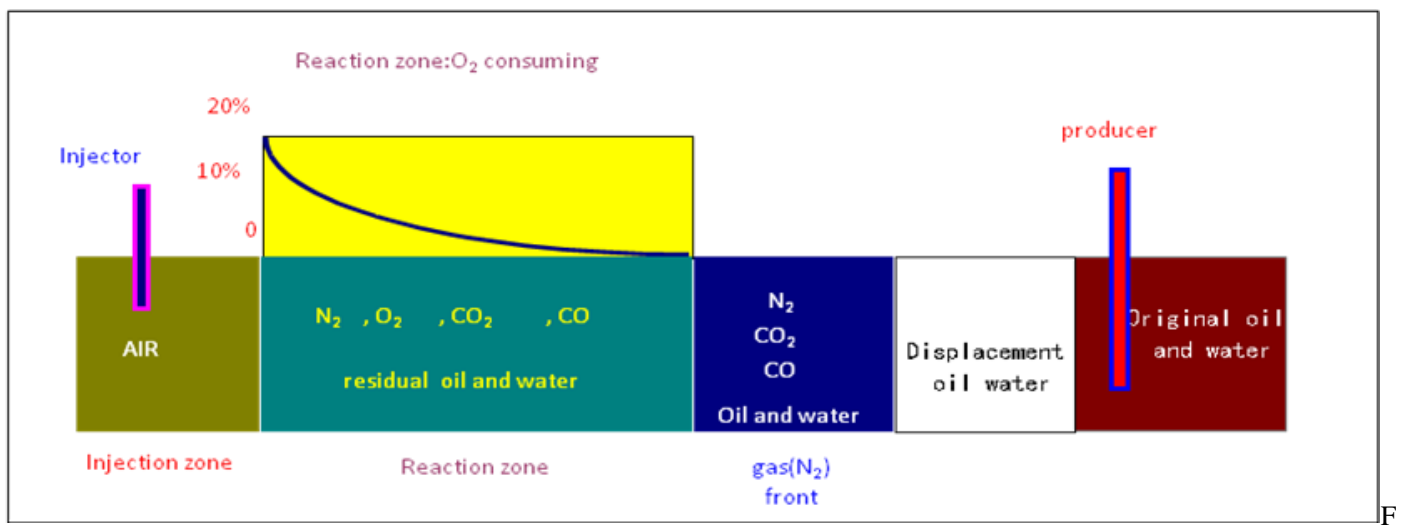

Figure1. The reservoir feature of the light oil air injection

In the process of site operation, resurgence of reservoir is very difficult, this shows the importance of stable combustion front in the field of engineering [12]. In general, the air injection can achieve $10 \mathrm{~cm}$ high temperature combustion front in the process of development, and the laboratory high temperature combustion front range is about 1 $\sim 2 \mathrm{~cm}$. Air into the reservoir and the crude oil react with oxygen and organic matter happen off key reactions: when the gas injection rate reaches a certain value, through the heat dissipating capacity of the rock in the reservoir less than putting the oxidation reaction heat and the reservoir temperature will rise. In this case, the crude oil ignite spontaneously under the action of oxygen, and form a oxidation leading edge in the reservoir, oxygen is consumed in the thermal belt. The size of the thermal zone with air injection rate, the characteristics of reservoir and oil. Oxidation front light oil reservoir temperature can reach $200 \sim 350{ }^{\circ} \mathrm{C}$, the gas is mainly from the burning of $\mathrm{CO}$ and $\mathrm{CO}_{2}$.

A successful air displacement project to do the following [13] :

(1) Try to ensure that $100 \%$ of the oxygen consumption;

(2) Actual time and precise ignition front to start the oxidation;

(3) Accurate forecasting production horizon;

(4) The mastery of reservoir parameters such as gas injection rate, starting temperature stable combustion front and spread regularly.

Make sure it is effective that the reservoir in the development process of oxygen consumption, we must form a stable displacement front, including the start of the front edge, front edge to maintain and spread. Front started at home and abroad have many successful ways: for example, adding oxygen slug, starting the catalyst light, etc. A steady front and its spread is the most important problem to be solved in the process.

Although air injection development technology (AIP) and the technology of ISC (ISC) has some discrepancy on the principle and application, but due to lacking of the cognition to the light oil air injection development concept, people usually simply extend the concept of fire flooding observation to light oil air injection in the development process.

\section{HOME AND ABROAD AIR INJECTION EFFICIENCY AND SAFETY FACTORS OF OXYGEN CONSUMPTION DEVELOPMENT INSTANCE ANALYSIS}

Light oil air injection development is widely used in the beginning of 1994, in Wisley basin, north and south Dakota areas of the United States are recorded, and these is no indoor experiments of field experiments, the main reason for the gas injection development is to replace the water injection development and find a new way of displacement. There is danger in the whole process in Air injection, every link must take safety measures, mainly to prevent the explosion problem in the process of air injection. Air process, Greeves[14,11], experimental study on the displacement, for the majority of light crude oil, low rate of injection air for oxygen consumption completely. Wisley basin oilfield is a fractured low permeability carbonate reservoir, which is one of the finest examples of air displacement project to be more successful, began in 1986, gas injection stops several times due to various reasons, during 1991-1993 annual outgassing of $\mathrm{CO}_{2}, \mathrm{~N}_{2}$ and hydrocarbon and gas tracer, showed that $\mathrm{O}_{2}$ was completely consumed [15]. ZhongYuan oilfield 12-32, Hu12-36 $\mathrm{O}_{2}$ content in the gas well output are within $3 \%$, which were below the safe concentration range [16].

At home and abroad for the safety oxygen content under the condition of explosion proof of air injection limit research is little, China university of petroleum (eastern China) RenShaoran[17,18] is researching for air injection in a few years in the development process of reservoir safety problems by indoor experiment (Fig.2) and numerical simulation technology for combustible gas 
explosion lowerest limit number of oxygen atoms to achieve complete combustion need to estimate the critical oxygen concentration. Through studies have shown that, for most of the oil product, oxygen content security restrictions under atmospheric pressure is about $10 \%$, oxygen content is lower than this value, even if in flame wouldn't be an explosion. And in the process of production, experiment and some foreign companies set the condition of oxygen content of safety standards to 5\%; In addition, pipeline corrosion should also be taken into consideration in the process of air injection [19]. Site operation usually choose for production wells in accurate time analysis of gas composition, danger alarm output, adding corrosion inhibitors reduce air for pipeline corrosion, leaning oxygen injection and other methods to eliminate the explosion danger[20]. The university of Calgary M.R.Fassihi researching for Holt Sand Unit[21] air displacement project sums up the experience and lessons, believe that site operation process, not only for different time monitor output well air content, but also for the ground conditions (temperature, pressure, etc.) and the analysis of production of oil and gas ratio should be taken into consideration. In addition, an observation well is also used as the observation of spread oxidation front and its characteristics.

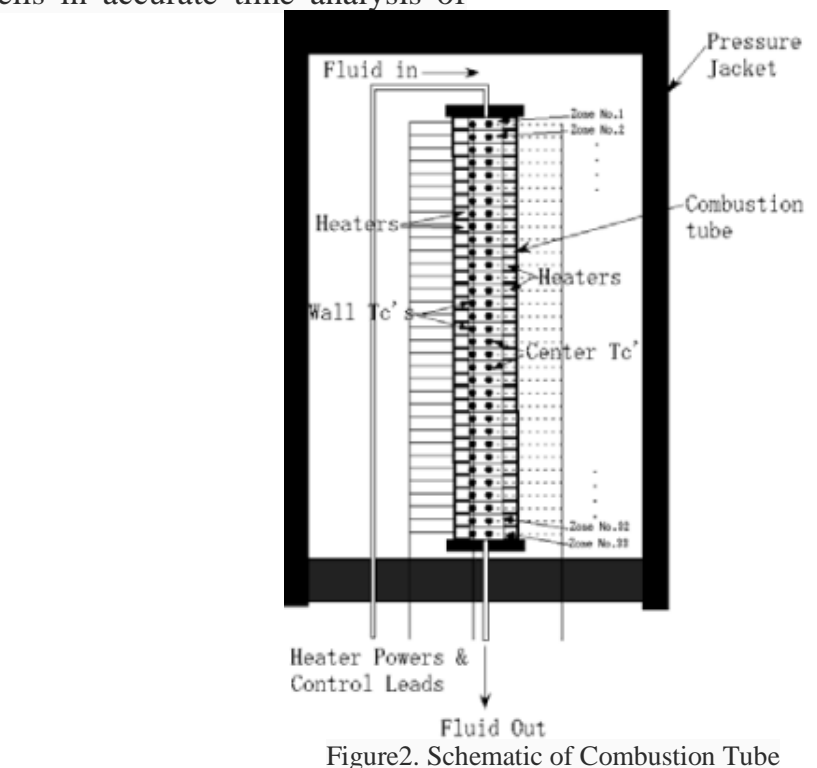

\section{IV.CONCLUSION}

(1) The key to Light oil air injection development of efficient oxygen oxidation is front started and oxidation stable transmission of the front, the oxidation in the process of development of startup mode is voluminous, while maintaining stable transmission of oxidation front in air injection is a key factor for the development of the technology for efficient oxygen consumption.

(2) For light oil reservoir development, it is necessary to go on a crude oil oxidation kinetics experiment, to explore based parameter of oxygen consumption and heat release characteristics of crude oil, crude oil oxidation kinetics of basic research to enhance oil recovery in the process of air injection has an important significance.

(3) Indoor air injection development of efficient oxygen experiment has been successful, displacement of oxygen content in accordance with less than $5 \%$ at the end of output during the safety limits. But for field development, the output end of oxygen still need accurate time monitoring to ensure the safety in production, monitoring to the oxygen content exceeds bid, need accurate time to shut-in until the well is open again when oxygen concentration is less than the critical oxygen content.

\section{REFERENCES}

[1] Oren, P.E, Billiotte, J, and Pinczewski, W.V. : "Mobilization of Water flood Residual Oil by Gas injection for water-Wet Conditions", paper SPE/DOE 20185 presented at the SPE/DOE seventh Symposium on Enhanced Oil recovery in Tursa, April 22-25, 1990.

[2] Naylor, P., Sargent, N. C., Tilsed, A.P. and Frorup, M. D.: "Oil Relative permeability for Gravity Drainage Based on in-Situ Saturation Measurement", paper SPE 23101 presented at Offshore Europe Conference in Aberdeen, 3-6 September 1991.

[3] Gregory, A. T.: "DTI's improved Oil Recovery Strategy", TransIChemE (1994) Part A VOI72, 137.

[4] Fassihi M R,Yannimaras . Economics of light oil air injection projects [ C ] . SPE 35393, 1996.

[5] Turta, A.:"In-Situ Combustion-From Pilot to Commercial Application," Proc., Field Applications of In-Situ Combustion-Past Performance/Future Application Symposium, Tulsa, Oklahoma (1994).

[6] Moritis, G.: "EOR Weathers Low Oil Prices," Oil and Gas J. (20 March 2000) 39. 
[7] Turta, A. and Pantazi, I. : "Development of In-Situ Combustion on an Industrial Scale at Videle Field, Rumania," SPERE(November 1986) 556.

[8] Carcoana, A. et al.: "In-Situ Combustion. An Effective Method to Enhance Oil Recovery in Romania," paper presented at the 1983 World Petroleum Congress, London, 28 August-2 September.

[9] Xinyu Zuo. With the air injection (LTO) residual low viscosity method to improve oil recovery factor:Foreign oilfield engineering.

[10] YouWei Jiang, YiTang Zhang,etc. mechanism of Air injection of low permeability reservoir development.Petroleum Exploration an Development.

[11] Taber J J . EOR screening criteria revisited [ M ] . DexasA\& M, 1997.

[12] PingGuo, YanWang, etc. Light oil reservoir air injection combustion tube test :Journal of China University of Petroleum(Edition of Social Sciences).

[13] A.T.Turta and A.K.Singhal.:''Reservior Engineering Aspects of Light-Oil Reservior by Air Injection,"paper presented at the 2001 SPE Reservoir Evaluation \& Engineering,Alberta

[14] M.Graves,S.R.Ren.et al.: "Improved Residual Light Oil Recovery by Air Injection(LTO Process), " presented at the 49th Annual Technical Meeting,June 8 - 10, 1998, in Calgary, Alberta. Abstract submitted for review December 10, 1997.
[15] Gutierrez D.,Miller R. J., Taylor A. R.et al., "Buffalo Field High-Pressure Air Injection Projects:Technical Performance and Operational Challenges '[J]. SPE Reservoir Evaluation 81 Engineering,2009,12(4); 542-550.

[16] HaitaoGuo, XueFengLi , BinZhao, etc, High permeability, high water cut oil reservoir air injection foam flooding pilot test.:Oilfield Chemistry.

[17] YaJuanJi , LePingZhou, etc. The air injection process explosion experimental research:Chinese journal of safety science.

[18] HongMinYu , JingLuanLI , etc. Air injection production oil well output gas explosion characteristics:Journal of China University of Petroleum(Edition of Social Sciences).

[19] QuanZhou , ShaoRanRen , etc. Air injection displacement in the process of corrosion and corrosion inhibitor filling process:Corrosion and protection..

[20] AiMinShao, AiShanLi, etc. Low permeability oil reservoir air injection displacement safety control technology research: NeijiangTechnology.

[21] M.R.Fassihi,SPE,R.G.Moore,SPE.et al., "Safety Consideration for Air Injection into Light Oil Reserviors "presented at the SPE Improved Oil Recovery Symposium held in Tulsa ,Oklahoma,USA,12-16 April 2014. 